\title{
Adverse functions of IL-17A in experimental sepsis
}

\author{
Michael A. Flierl, ${ }^{*}, 1$ Daniel Rittirsch, ${ }^{*, 1}$ Hongwei Gao, ${ }^{\ddagger, 1}$ Laszlo M. Hoesel,* \\ Brian A. Nadeau,* Danielle E. Day,* Firas S. Zetoune,* J. Vidya Sarma,* \\ Markus S. Huber-Lang, ${ }^{\S}$ James L. M. Ferrara, ${ }^{\dagger}$ and Peter A. Ward ${ }^{*, 2}$ \\ *Department of Pathology, and ${ }^{\dagger}$ Departments of Pediatrics and Internal Medicine, University of \\ Michigan Medical School, Ann Arbor, Michigan, USA; ${ }^{\ddagger}$ Department of Biochemistry and Molecular \\ Biology, University of North Dakota Medical School, Grand Forks, North Dakota, USA; and \\ ${ }^{\S}$ Department of Traumatology, Hand- and Reconstructive Surgery, University of Ulm Medical School, \\ Ulm, Germany
}

ABSTRACT IL-17A is a proinflammatory cytokine produced by a variety of cells. In the current study, we examined the role of IL-17A in sepsis induced in mice by cecal ligation and puncture (GLP). IL-17A levels, which rose time-dependently in plasma after CLP, were not affected in the absence of $\alpha \beta \mathrm{T}$ cells or neutrophils. In sharp contrast, $\gamma \delta \mathrm{T}$ cell-knockout or $\gamma \delta \mathrm{T}$ cell-depleted mice displayed baseline IL-17A plasma levels after CLP. Neutralization of IL-17A by two different antibodies improved sepsis (survival from $\sim 10 \%$ to nearly $60 \%$ ). Unexpectedly, antibody treatment was protective, even when administration of antiIL-17A was delayed for up to $12 \mathrm{~h}$ after CLP. These protective effects of IL-17A blockade were associated with substantially reduced levels of bacteremia together with significant reductions of systemic proinflammatory cytokines and chemokines in plasma. In vitro incubation of mouse peritoneal macrophages with lipopolysaccharide (LPS) in the copresence of IL-17A substantially increased the production of TNF- $\alpha$, IL-1 $\beta$, and IL- 6 by these cells. These data suggest that, during experimental sepsis, $\gamma \delta \mathrm{T}$ cell-derived IL-17A promotes high levels of proinflammatory mediators and bacteremia, resulting in enhanced lethality. IL-17A may be a potential therapeutic target in sepsis.-Flierl, M. A., Rittirsch, D., Gao, H., Hoesel, L. M., Nadeau, B. A., Day, D. E., Zetoune, F. S., Sarma, J. V., Huber-Lang, M. S., Ferrara, J. L. M., Ward, P. A. Adverse functions of IL-17A in experimental sepsis. FASEB J. 22, 2198-2205 (2008)

Key Words: $\gamma \delta \cdot T$ cells $\cdot$ survival $\cdot$ colony-forming units $\cdot$ cytokines $\cdot$ chemokines

DESPITE TREMENDOUS SCIENTIFIC and clinical efforts, sepsis continues to be an incalculable and enigmatic disease. In fact, the mortality of patients with septic shock has increased over the past years (1), and septicemia ranks now as the 10th leading cause of death in the United States, as opposed to 13th in 1990 (2). It is now becoming apparent that sepsis might not be a solitary, clearly defined disease, but rather a puzzling interplay of various biological systems and cascades with the immune system, resulting in a highly variable clinical picture. As a result, we are only able to use crude clinical parameters like body temperature, leukocyte count, heart rate and respiratory rate in an attempt to define sepsis. Thus, many clinicians refer to sepsis as a syndrome rather than a disease. In parallel with the difficulties encountered in the clinical setting, sepsis research has suffered from many setbacks. In many cases, promising experimental strategies have failed to be successful in the clinical setting $(3,4)$. Therefore, there is a compelling need to broaden our comprehension of the pathophysiology of inflammation and its regulation. Recently, novel mediators of sepsis and inflammation have been discovered, such as HMGB-1 (5, 6), putting new promising therapeutical targets on the murky horizon. Further, the discovery of the IL-17 cytokine family has provided a new pathway for crosstalk between adaptive and innate immunity. To date, several sources of IL-17 have been identified: Th17 cells, CD8 T cells, natural killer (NK) cells, $\alpha \beta \mathrm{T}$ cells, $\gamma \delta \mathrm{T}$ cells, and neutrophils (7). It is now becoming clear that IL-17A (the first described member of the IL-17 family) is a mediator of neutrophil stimulation and mobilization by $\mathrm{T}$ lymphocytes (8). This presents IL-17A with a uniquely powerful position at the interface between adaptive and innate immunity. Thus, it is not surprising that the IL-17 family has been shown to be involved in various physiological and pathophysiological processes such as granulopoesis, defense against bacteria, rheumatoid arthritis, allograft rejection, tumor modulation, and asthma and allergic reactions ( 7 , 9-16).

In the current study, we sought to evaluate the role of IL-17A during experimental sepsis induced by CLP in mice. Given the proinflammatory effects of IL-17A in various pathophysiological settings, we hypothesized that elevated systemic levels of IL-17A during sepsis might be harmful, connecting the inflammatory arsenal of adaptive and innate immunity and ultimately resulting in the well-described inflammatory downward

\footnotetext{
${ }^{1}$ These authors contributed equally to this work.

${ }^{2}$ Correspondence: Department of Pathology, The University of Michigan Medical School, 1301 Catherine Rd., Ann Arbor, MI 48109-0602, USA. E-mail: pward@umich.edu doi: $10.1096 /$ fj.07-105221
} 
spiral occurring in sepsis. In the setting of experimental sepsis, we identify $\gamma \delta \mathrm{T}$ cells, but not $\alpha \beta \mathrm{T}$ cells or neutrophils, as the source of elevated plasma IL-17A levels following CLP. Moreover, we describe protective effects of IL-17A blockade on sepsis mortality, effective even when carried out up to $12 \mathrm{~h}$ after CLP, associated with reduced blood-borne bacteria (colony forming units, CFUs) and decreased levels of proinflammatory cytokines and chemokines. Accordingly, IL-17A may be a target in human sepsis.

\section{MATERIALS AND METHODS}

\section{Animals, anesthesia, and experimental sepsis}

All procedures were performed in accordance with the National Institutes of Health guidelines and the University Committee on Use and Care of Animals (UCUCA), University of Michigan. Specific pathogen-free, male C57BL/6, $\alpha \beta \mathrm{T}$ cell-knockout (B6.129S2-Tcra $\left.a^{\operatorname{mimom}} / \mathrm{J}\right)$ or $\gamma \delta \mathrm{T}$ cell-knockout (B6.129P2-Tcrd $\left.{ }^{\mathrm{tm} 1 \mathrm{Mom}} / \mathrm{J}\right)$ mice $(9-10 \mathrm{wk}$ of age, 22-25 g; Jackson Laboratories, Bar Harbor, ME, USA) were used. Both knockout mice are on a C57BL/6 background. Intraperitoneal ketamine (100 mg/kg body weight) (Fort Dodge Animal Health, Fort Dodge, IA, USA) was used for anesthesia and intraperitoneal xylazine $(13 \mathrm{mg} / \mathrm{kg}$ body weight) (Bayer Corp. Shawnee Mission, KS, USA) for sedation. Experimental sepsis was induced by CLP, as described previously (17). In short, a $1-\mathrm{cm}$ abdominal midline incision was made; the cecum was exposed, ligated, and punctured through and through with a 19-gauge needle; and a small portion of feces was pressed out to ensure persistence of the punctures. After repositioning of the bowel, the abdomen was closed in layers using 6-0 surgical sutures (Ethicon Inc., Somerville, NJ, USA) and metallic clips. Before and after the surgery, animals had unrestricted access to food and water.

\section{Plasma collection}

At given time points after CLP, whole blood was collected by cardiac puncture into syringes containing anticoagulant citrate dextrose (ACD; Baxter, Deerfield, IL, USA) in a 9:1 ratio. Samples were centrifuged (3000 rpm, $10 \mathrm{~min}, 4^{\circ} \mathrm{C}$ ); plasma was obtained and immediately stored at $-80^{\circ} \mathrm{C}$ until further analysis.

\section{Cytokine/chemokine measurements}

Plasma was harvested as described above. The following mouse ELISA kits were used: TNF- $\alpha$, IL-1 $\beta$, IL-6, IL-10, MIP-2, MIP-1 $\alpha$, MCP-1, IL-17, TGF $\beta$ (all R\&D Systems, Minneapolis, MN, USA). For quantification of HMGB1, a commercially available ELISA kit (Shino-Test Corporation, Kanagawa, Japan) was used. All experiments were performed according to the manufacturer's protocol.

\section{$\gamma \delta \mathrm{T}$ cell depletion}

$\gamma \delta \mathrm{T}$ cell depletion was induced using $500-\mu \mathrm{g}$ hamster antimouse TCR $\gamma \delta$ monoclonal antibodies (Biolegend, San Diego, CA, USA) 5 days before CLP, as described previously (18, 19). Control animals received an intraperitoneal injection of isotype-matched Armenian hamster IgG (500 $\mu \mathrm{g}$; Biolegend, San Diego, CA, USA).

\section{Anti-IL-17A antibodies}

A specific neutralizing monoclonal anti-mouse IL-17A antibody was obtained from eBioscience (San Diego, CA, USA) and a polyclonal anti-mouse IL-17A antibody from R\&D Systems. The monoclonal neutralizing antibody was used in all experiments, while the polyclonal $\mathrm{R} \& \mathrm{D}$ antibody was exclusively used to confirm the survival data (data not shown). Both antibodies have been characterized by the manufacturers to specifically neutralize mouse IL-17A and contain $<0.001$ endotoxin $/ \mu$ g protein. For in vivo neutralizing experiments, $45 \mu \mathrm{g}$ of anti-IL-17A or control IgG (Jackson ImmunoResearch, West Grove, PA, USA) was administered intravenously in a total volume of $200 \mu \mathrm{l}$ at the time of CLP. In some survival studies, infusions of blocking antibodies to IL-17A were delayed 6 or $12 \mathrm{~h}$ after CLP where indicated.

\section{Determination of CFUs in blood}

Blood was obtained by cardiac puncture and was drawn into syringes containing $10 \%$ citrate. Following appropriate dilution in $0.9 \%$ saline, $100-\mu \mathrm{l}$ samples were plated in duplicates on 5\% sheep blood agar (Remel, Lenexa, KS, USA) and incubated for $24 \mathrm{~h}$ at $37^{\circ} \mathrm{C}$ under aerobic conditions. CFUs were then determined and multiplied by the dilution factor.

\section{Isolation and incubation of murine peritoneal macrophages}

Mouse peritoneal macrophages were harvested 5 days after intraperitoneal injection of $1.5 \mathrm{ml}$ thioglycolate (BD Biosciences, Sparks, MD, USA; $2.4 \mathrm{~g} / 100 \mathrm{ml}$ ) by peritoneal lavage with PBS. After washing, the purity of cell suspension was $>95 \%$ macrophages. Macrophages $\left(5 \times 10^{6}\right.$ per experimental condition) were allowed to adhere to tissue culture plates over $2 \mathrm{~h}$ and incubated in RPMI medium containing $0.5 \% \mathrm{BSA}$ for $4 \mathrm{~h}$ at $37^{\circ} \mathrm{C}$. Recombinant, endotoxin-free mouse IL-17A was obtained from R\&D Systems, and LPS (Escherichia coli 0111:B4) was purchased from Sigma-Aldrich (St. Louis, MO, USA).

\section{Statistical analysis}

All values are expressed as means \pm SE. Data were analyzed with a one-way ANOVA, and individual group means were then compared with a Student-Newman-Keuls test. Differences were considered significant when $P \leq 0.05$.

\section{RESULTS}

\section{Elevated IL-17A levels during sepsis}

Plasma levels of IL-17A as a function of time were evaluated in mice following CLP. There was a progressive rise in plasma levels of IL-17A, peaking at $12 \mathrm{~h}$ after CLP, followed by a rapid decline to baseline values at 24 h (Fig. 1A).

\section{Systemic IL-17A requires $\gamma \delta$ T cells but not $\alpha \beta T$ cells or neutrophils}

Because IL-17A has been reported to be produced by $\alpha \beta \mathrm{T}$ cells, $\gamma \delta \mathrm{T}$ cells, NK cells, CD4 T cells, and neutrophils (7), we sought to determine the cell population chiefly responsible for the elevated levels of 
A
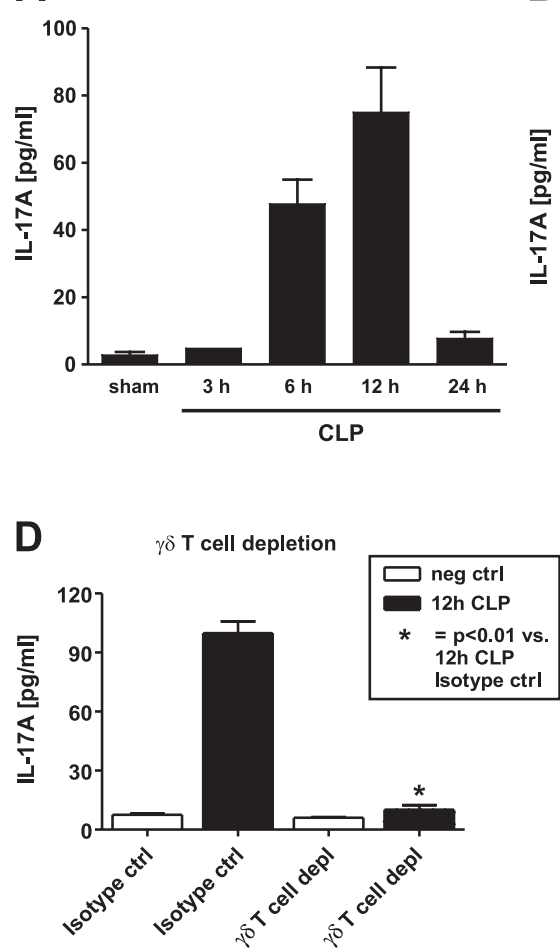

B

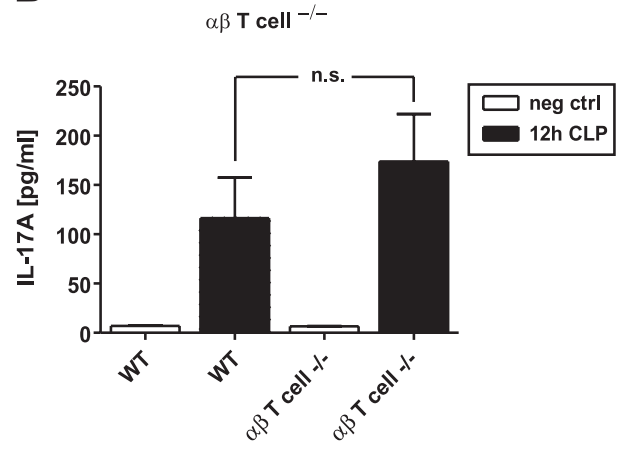

C

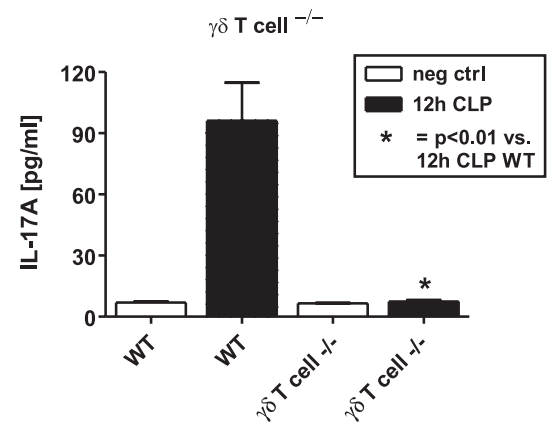

IL-17A after CLP. Experimental sepsis was induced by CLP in wild-type, $\alpha \beta$ T cell-knockout mice (B6.129S2$\left.T c r a^{\mathrm{tm} 1 \mathrm{Mom}} / \mathrm{J}\right)$ or $\gamma \delta \mathrm{T}$ cell-knockout mice (B6.129P2$T c r d^{\mathrm{tm} 1 \mathrm{Mom}} / \mathrm{J}$ ), comparing plasma levels of IL-17A $12 \mathrm{~h}$ after CLP to wild-type littermates. As shown in Fig. $1 B$, levels of IL-17A were not significantly altered in $\alpha \beta \mathrm{T}$ cell-knockout mice when compared to wild-type littermates. In sharp contrast, there was complete abolition of systemic IL-17A buildup in septic animals lacking $\gamma \delta$ $\mathrm{T}$ cells (Fig. 1C), suggesting a key role for $\gamma \delta \mathrm{T}$ cells in the sepsis-induced production of systemic IL-17A. These findings were confirmed in CLP mice depleted of $\gamma \delta \mathrm{T}$ cells using a monoclonal hamster antibody when compared to isotype IgG-treated mice (Fig. $1 D)$. Neutrophils (PMNs) have been reported to contain intracellular IL-17A message and protein, but release of free, soluble IL-17A from PMN has not been reported (20-22). In further experiments, blood PMNs were depleted using a monoclonal antibody, Ly-6G. With blood PMNs falling to less than 5\% of normal blood values, there was no significant reduction in plasma levels of IL-17A after CLP (data not shown), indicating that during CLP-induced sepsis, PMNs were not a significant source of IL-17A. Moreover, CD4 T cell-knockout mice (B6.129S6-Cd4) or animals that were $\mathrm{T}$ cell depleted with a monoclonal antibody targeting CD4 cells (GK1.5) (23) showed no significant changes in IL-17A levels $12 \mathrm{~h}$ after CLP in comparison to $\mathrm{CD} 4^{+/+}$mice and isotype IgG-treated littermates, respectively (data not shown). These data indicate that $\gamma \delta \mathrm{T}$ cells are the source of IL-17A in the CLP model of experimental sepsis.

\section{Neutralization of IL-17A in CLP mice treated with monoclonal anti-IL-17A}

To determine the in vivo efficacy of a neutralizing monoclonal rat IgG antibody to mouse IL-17A, levels of IL-17A were determined in plasma obtained from animals treated intravenously with either control IgG or neutralizing monoclonal anti-IL-17A $12 \mathrm{~h}$ after CLP. As determined by ELISA, mice treated with an isotype control IgG displayed similar levels as wild-type mice, while administration of $45 \mu \mathrm{g}$ monoclonal anti-IL-17A reduced plasma levels of IL-17A to negative control levels (data not shown).

\section{Improved survival in CLP after anti-IL-17A treatment}

To investigate the role of IL-17A in CLP-induced sepsis, a neutralizing monoclonal antibody to IL-17A (as described above) was given intravenously at the time of CLP or at 6 or $12 \mathrm{~h}$ after CLP. Mice treated with an isotype control $\mathrm{IgG}$, administered at the same time points, served as a control. As shown in Fig. 2A, control IgG-treated mice displayed $8 \%$ survival by day 7 (bottom line). In contrast, when mice were administered anti-IL-17A at the time of CLP, survival was $58 \%$ at day 7 (top line, Fig. $2 A, P<0.05$ ). To investigate whether delayed infusion of anti-IL-17A would still protect in the setting of CLP, intravenous infusion was delayed until $12 \mathrm{~h}$ after CLP, resulting in survivals of $33 \%(P<0.05)$, indicating that delayed infusion of anti-IL-17A was still significantly protecting against CLP-induced sepsis (middle line, Fig. 2A). Delay of anti-IL-17A infusion until $6 \mathrm{~h}$ after CLP also resulted in an improved survival 
A

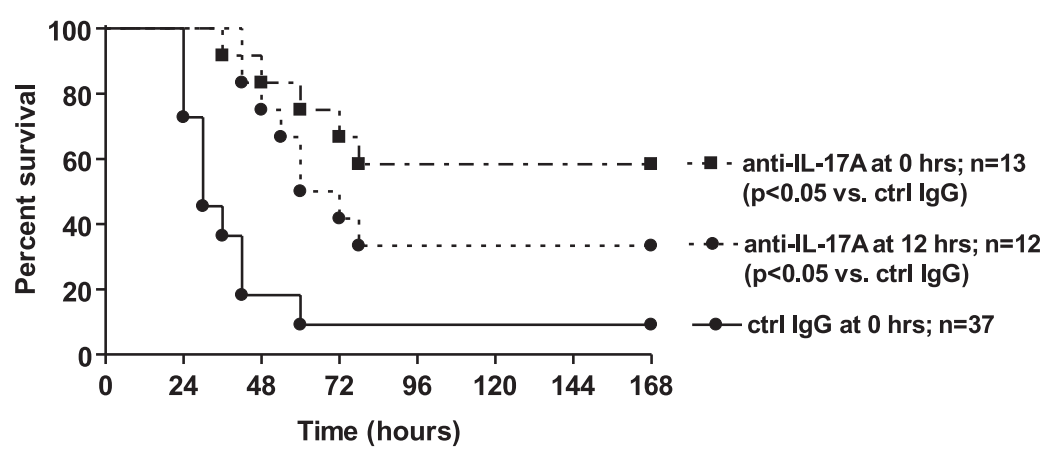

C

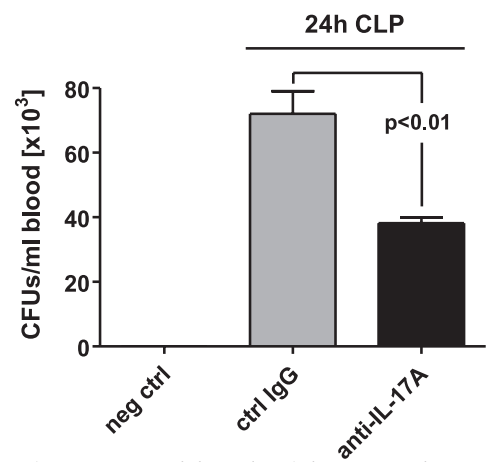

D

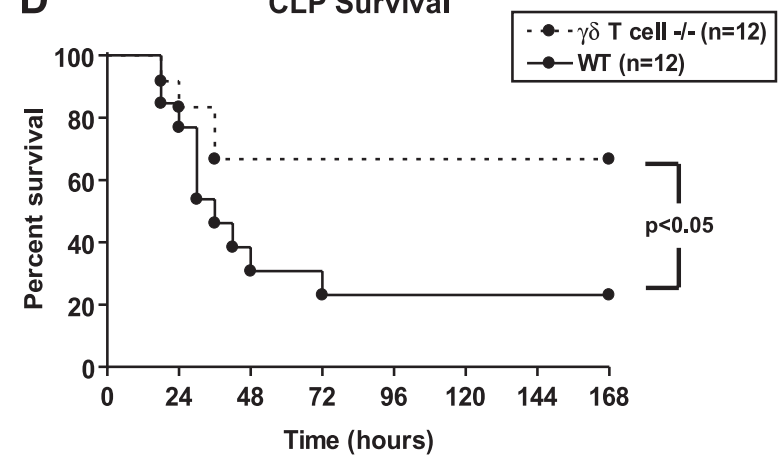

B

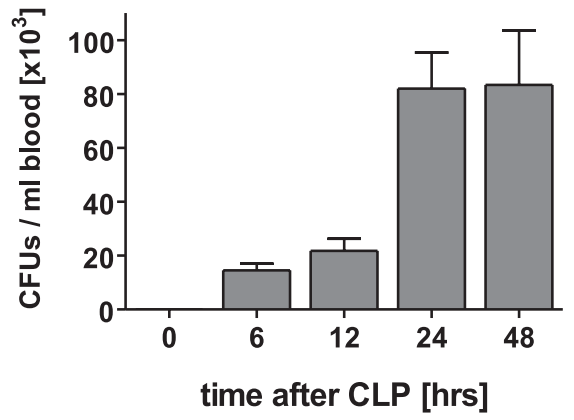

Figure 2. A) Survival curves of CLP mice infused i.v. with $45 \mu \mathrm{g}$ control IgG (ctrl IgG) treatment or neutralizing monoclonal anti-IL-17A at time 0 or $12 \mathrm{~h}$ after CLP. Numbers of mice used for each condition are shown in the frame. $B$ ) Bacterial CFUs in blood as a function of time after CLP. All bars are presented as mean \pm sE; $n=10 /$ group. C) CFUs in blood $24 \mathrm{~h}$ after sham or CLP surgery in mice were treated i.v. at time 0 with either control IgG (ctrl IgG) or monoclonal anti-IL-17A (both $45 \mu \mathrm{g}$ ). CFUs were determined using sheep blood agar under aerobic conditions. $n=5$.

$D)$ CLP survival curves of $\gamma \delta \mathrm{T}$ cell-knockout mice $(n=12)$ vs. wild-type littermates $(n=12)$.

of $40 \%$ ( $P<0.05$ vs. ctrl IgG-treated animals) (data not shown). When mice were given a different neutralizing antibody to IL-17A (polyclonal) at time 0 , survival was $62 \%$ at day 5 , resulting in a similar improvement of survival (data not shown).

\section{IL-17A blockade reduces bacteremia after CLP}

To determine the effects of in vivo blockade of IL-17A after CLP might be linked to the level of systemic bacteremia, anticoagulated blood was collected $0-48 \mathrm{~h}$ after CLP by cardiac puncture, and aerobic blood cultures were obtained using sheep blood agar plates. After $24 \mathrm{~h}$ of incubation at $37^{\circ} \mathrm{C}$, CFUs were quantified. As shown in Fig. 2B, blood CFUs peaked at 24 and $48 \mathrm{~h}$ after CLP. Accordingly, CLP was induced in mice treated with either anti-IL-17A or control IgG, and blood samples were obtained $24 \mathrm{~h}$ after CLP and plated for aerobic CFUs. As shown in Fig. 2C, anti-IL-17Atreated mice displayed a significant reduction in CFUs when compared to control IgG-treated littermates $24 \mathrm{~h}$ after CLP. These data suggest that, during CLP, IL-17A reduces the ability of mice to clear blood-borne bacteria and that with its blockade, the levels of bacteremia are reduced.

$\gamma \delta \mathrm{T}$ cell-knockout mice display improved survival during experimental sepsis

Because we have identified $\gamma \delta \mathrm{T}$ cells as the main source of IL-17A production during experimental sep- sis (Fig. 1) and because blockade of IL-17A was protective during CLP (Fig. 2A), we hypothesized that $\gamma \delta \mathrm{T}$ cell-knockout mice might display improved survival during CLP. As shown in Fig. 2D, $\gamma \delta \mathrm{T}$ cell $^{-/-}$mice exhibited greatly improved survival during CLP-induced experimental sepsis when compared to C57/BL6 wild-type littermates.

\section{IL-17A increases macrophage in vitro production of proinflammatory cytokines}

To evaluate whether elevated levels of IL-17A during sepsis might also be related to elevated levels of proinflammatory cytokines, murine peritoneal macrophages were obtained and incubated with either LPS (50 $\mathrm{ng} / \mathrm{ml})$, IL-17A $(10 \mathrm{pg} / \mathrm{ml})$, or a combination of LPS $(50 \mathrm{ng} / \mathrm{ml})$ and increasing doses of IL-17A $(1 \mathrm{pg} / \mathrm{ml}$ to $10 \mathrm{ng} / \mathrm{ml}$ ). As shown in Fig. 3, the addition of IL-17A greatly potentiated the LPS-induced production of TNF- $\alpha$, IL-1 $\beta$, or IL- 6 by 2 - to 3 -fold in a dose-dependent manner, whereas IL-17A alone $(10 \mathrm{pg} / \mathrm{ml})$ only slightly augmented the baseline proinflammatory mediator response. This effect was observed over a wide range of doses ( $1 \mathrm{pg}$ to $10 \mathrm{ng}$ ). Interestingly, these effects were exclusively observed for proinflammatory cytokines but not the proinflammatory chemokines MCP-1, MIP-1 $\alpha$, or MIP2 (data not shown). Collectively, these findings suggest that, in the copresence of LPS, IL-17A increases the in vitro production of proinflammatory cytokines by macrophages. 

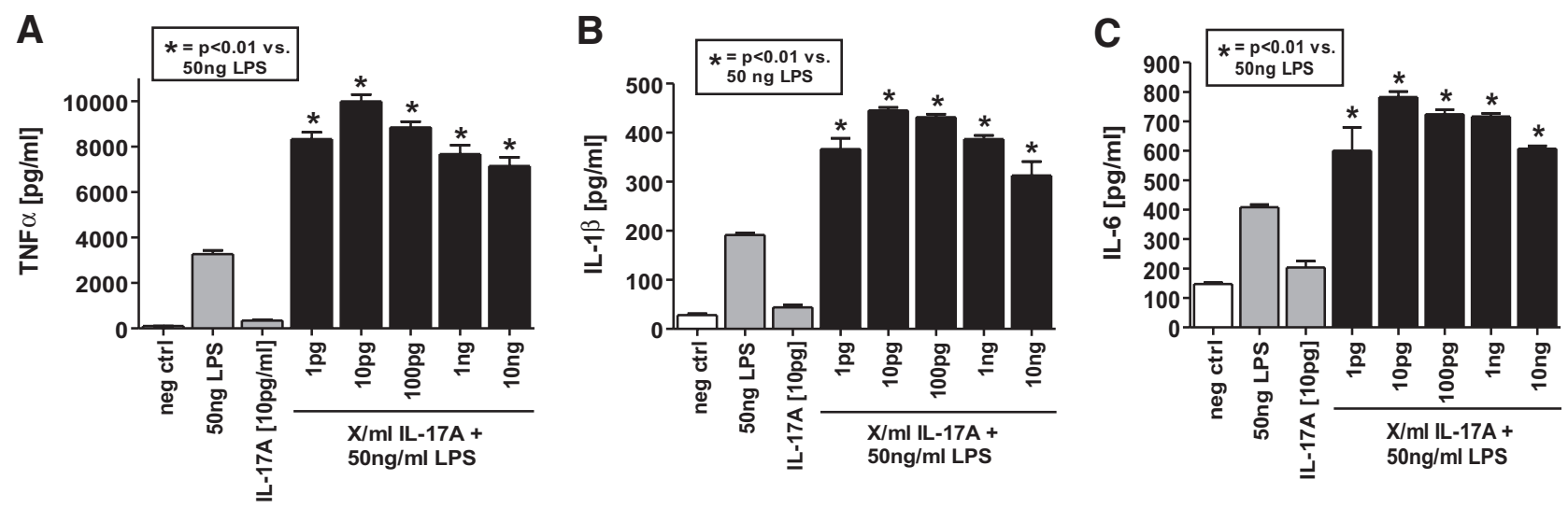

Figure 3. Incubation of elicited murine peritoneal macrophages $\left(5 \times 10^{6} / \mathrm{ml}\right)$ with HBSS (neg ctrl), LPS (50 ng/ml), recombinant IL-17A $(10 \mathrm{pg} / \mathrm{ml})$, or the combination of LPS $(50 \mathrm{ng} / \mathrm{ml})$ and varying doses of recombinant IL-17A for $4 \mathrm{~h}\left(37^{\circ} \mathrm{C}\right)$ in vitro. Analysis of cell supernatants for TNF- $\alpha(A)$, IL-1 $\beta(B)$, and IL-6 $(C)$ by ELISA. All bars are presented as mean \pm SE; $n=5$ /group.

\section{Blockade of IL-17A reduces plasma levels of proinflammatory cytokines and chemokines after CLP}

Given these in vitro observations, we sought to determine whether blockade of IL-17A in CLP mice affected the levels of inflammatory mediators in plasma. Mice were randomly assigned to three groups. The first group was given sham treatment, the second group was infused with $45 \mu \mathrm{g}$ of IgG immediately after CLP (control IgG treatment), and a third group was intravenously administered $45 \mu \mathrm{g}$ of monoclonal anti-IL-17A at the time of CLP. Plasma was obtained at time 0 (sham-treated mice) and $24 \mathrm{~h}$ after CLP (IgG- or anti-IL-17A-treated mice), since proinflammatory mediators peak in blood $24 \mathrm{~h}$ after CLP (unpublished data). There were very low or unmeasurable levels of mediators in plasma from all sham-treated mice (Fig. 4). In animals treated with nonspecific IgG, there were sharp increments in the cytokines TNF- $\alpha$, IL-1 $\beta$, IL- 6 , and in the chemokines MIP-1 $\alpha$, MIP-2, and MCP-1 in plasma $24 \mathrm{~h}$ after CLP (Fig. 4A-C, $F-H$ ). Levels of HMGB-1 were also increased after CLP (Fig. 4I). When CLP mice were infused with anti-IL-17A at time 0 , systemic levels of all proinflammatory mediators were substantially reduced, suggesting that IL-17A facilitates the systemic production of proinflammatory cytokines and chemokines and HMGB-1 after CLP. Interestingly, anti-IL-17A caused increases in levels of the anti-inflammatory cytokine IL-10 (Fig. 4D) and TGF $\beta$ (Fig. 4E).

\section{DISCUSSION}

The IL-17 family is emerging as an important regulator of the inflammatory response and has become the key to an expanding understanding of cytokine networks that coordinate and interlace innate and adaptive immunity (7). Lately, a distinct lineage of CD4 T cells, Th17 cells, has been identified as the main source of IL-17A and has clearly been the focus of recent research $(16,24-36)$. However, besides Th17 cells, other sources of IL-17A have been identified: $\alpha \beta$ T cells, $\gamma \delta$ T cells (37), NK cells, and neutrophils (7). In a recent study, patients suffering from trauma, systemic inflammatory response syndrome (SIRS), or sepsis syndrome were found to have a rapid and prolonged activation of $\gamma \delta \mathrm{T}$ cells but not $\alpha \beta \mathrm{T}$ cells, suggesting a significant role for $\gamma \delta \mathrm{T}$ cells as early responders during trauma, SIRS, and sepsis (38). It is now becoming evident that these cells are key players in bridging the innate and adaptive early immune responses. In line with the current study, in which we identified $\gamma \delta \mathrm{T}$ cells as the predominant source of IL-17A during sepsis (Fig. 1C, $D)$, recent studies reported that resident $\gamma \delta \mathrm{T}$ cells control neutrophil-mediated innate immune responses via the production of IL-17A $(15,37)$. After intraperitoneal injection of $E$. coli, the rapid and transient production of IL-17A was found to mainly originate from $\gamma \delta \mathrm{T}$ cells and assist in recruitment of neutrophils (15). Collectively, these data suggest that $\gamma \delta \mathrm{T}$ cellderived IL-17A enhances innate immunity via recruitment of neutrophils. This rapid recruitment of PMNs by IL-17A seems, in part, to be regulated by enhancement of chemokine gene expression (39). Interestingly, IL-17A and TNF- $\alpha$ seemed to act synergistically to achieve this goal. Although TNF- $\alpha$ initiated chemokine gene transcription through activation of NF- $\mathrm{B}$, IL-17A extended the half-life of mRNA via activator of NF-кB1 protein (Act-1) -dependent mechanisms (39). In the present study, we have also found synergistic effects of IL-17A on LPS-induced in vitro activation of peritoneal macrophages (Fig. 3). The requirement of Act-1 for IL-17A and IL-17A receptor (IL-17RA) -dependent signaling during the immune response has been confirmed in other studies $(40,41)$. Moreover, IL-17A has been reported to be a major orchestrator of sustained neutrophil mobilization and associated activity through induction of specific cytokines and colony-stimulating factors in resident lung cells (42).

By incubating cells with LPS in the copresence of various doses of IL-17A, we attempted to mimic septicemia and elevated IL-17A levels in vitro to investigate 
A

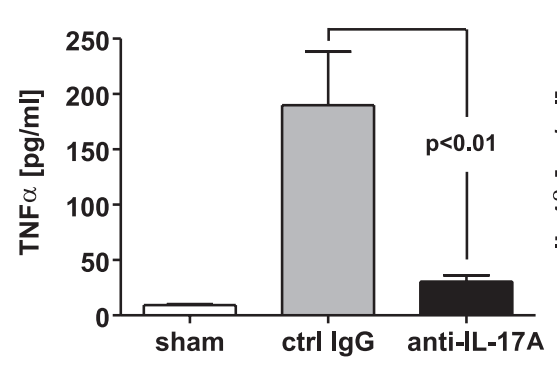

D

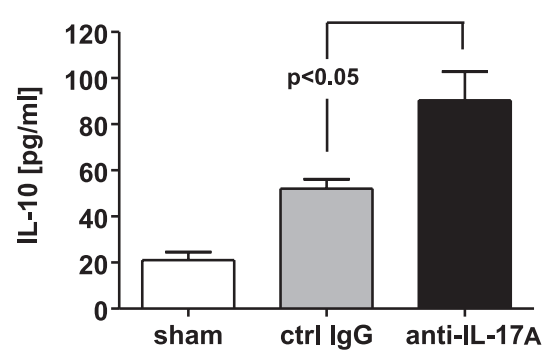

G

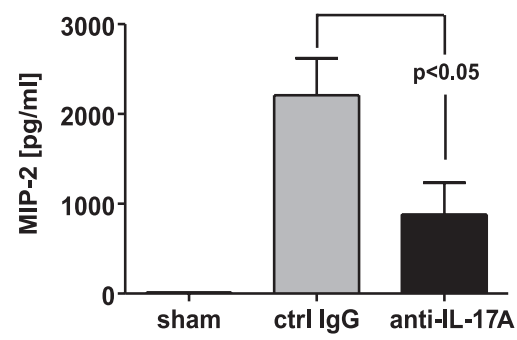

B

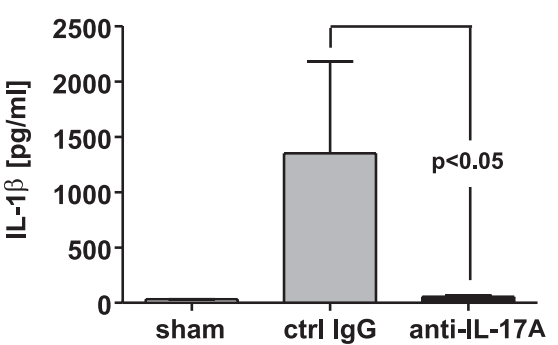

E

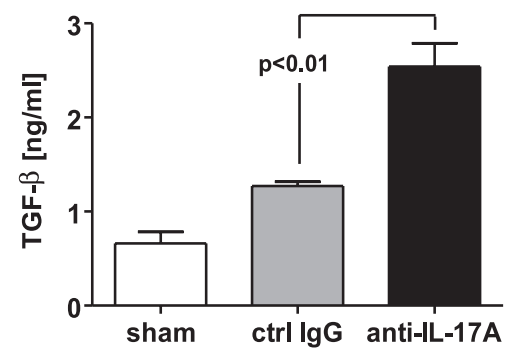

H

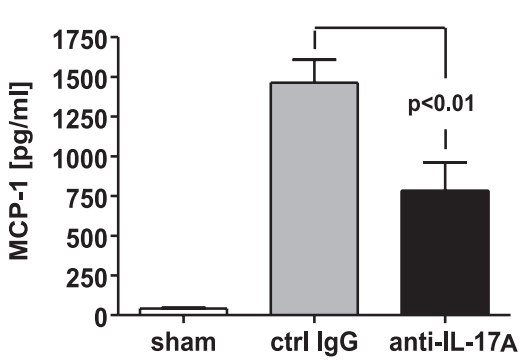

C

IL-6 24h CLP

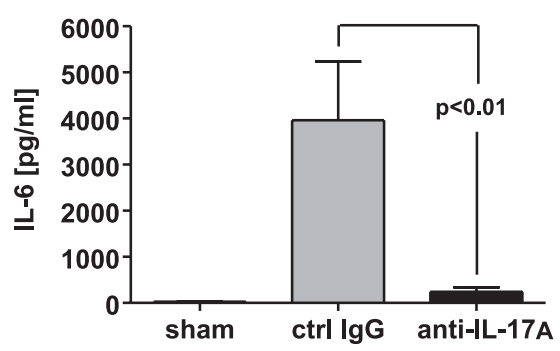

F

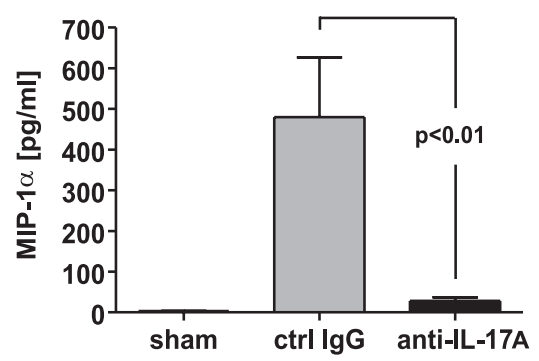

I

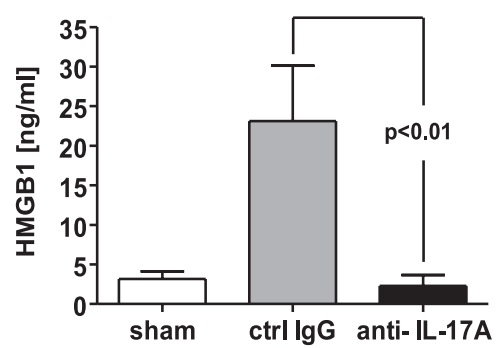

Figure 4. Effects of IL-17A blockade on appearance of cytokines and chemokines in plasma 24 h after CLP, using ELISA: A) TNF $\alpha$; $B$ ) IL-1 $\beta$; C) IL-6; D) IL-10; E) TGF $\beta ; F)$ MIP-1 $\alpha$; G) MIP-2; H) MCP-1; I) HMGB1. Plasma samples were obtained by cardiac puncture from sham-treated mice or CLP mice treated with $45 \mu \mathrm{g}$ control IgG (gray bars) or monoclonal anti-IL-17A (black bars; both administered at the time of CLP). All bars are presented as mean \pm SE; $n=5$ /group.

whether macrophage production of cytokines and chemokines can be altered by exposure to IL-17A and LPS. Interestingly, the copresence of IL-17A with LPS synergistically increased levels of the proinflammatory cytokines TNF- $\alpha$, IL-1 $\beta$, and IL-6 (Fig. 3), whereas levels of MCP-1, MIP-1 $\alpha$, and MIP-2 were not found to be increased under similar conditions. The exact molecular mechanism of this observation remains to be determined, but the data would suggest that IL-17A produced during sepsis can be implicated in the "cytokine storm," which connotes an unregulated development of inflammatory response.

IL-17A has been found to be elevated in a variety of inflammatory conditions, such as rheumatoid arthritis, pneumonia, systemic lupus erythematosus, allograft rejection, etc. $(43,44)$ Thus, it is not surprising that IL-17A acts on various cells, including neutrophils, fibroblasts, epithelial cells, and endothelial cells, inducing the expression of proinflammatory mediators such as IL-6, CXC chemokines, and matrix metalloproteinases (43). In the current study, we found reduced levels of proinflammatory cytokines and chemokines in septic animals treated with anti-IL-17A when compared to control IgG-treated littermates (Fig. 4) and that $\gamma \delta \mathrm{T}$ cells were the major source of sepsis-associated increased IL-17A levels (Fig. 1). Chung et al. (45) recently reported decreased concentrations of TNF- $\alpha$, IL- 6 , and IL-12 in $\gamma \delta \mathrm{T}$ cell-knockout animals during sepsis. It is tempting to speculate whether these decreased levels of proinflammatory mediators are in fact due to the absence of IL-17A in $\gamma \delta \mathrm{T}$ cell-knockout mice or $\gamma \delta \mathrm{T}$ cell-depleted animals during sepsis (Fig. $1 C, D$ ), as IL-17A significantly potentiates the inflammatory mediator production in macrophages in vitro (Fig. 3). Collectively, the data in the current report suggest that CLP causes increased levels of IL-17A in plasma, which enhances production of proinflammatory cytokines. The mechanism by which IL-17A causes enhanced levels of CFUs in blood after CLP is unclear, but it may be that the bactericidal function of blood neutrophils is in some manner compromised under such conditions. An analogous situation in sepsis has been shown to be related to uncontrolled generation of $\mathrm{C} 5 \mathrm{a}$, which paralyzes MAPK signaling pathways in neutrophils (46).

The unique position of IL-17A at the interface between innate and acquired immunity puts this mediator 
in the lead as a crucial signal for the reinforcement and crosstalk of host defense systems. Thus, IL-17A might constitute a useful target for therapeutic intervention in sepsis and other inflammatory settings.

We are indebted to Beverly Schumann and Sue Scott for their excellent assistance in the preparation of this manuscript. This study was supported by National Institutes of Health grants GM29507, GM61656, and HL-31963 (P.A.W.) and Deutsche Forschungsgemeinschaft grants DFG HU 823/ 2-2 and HU 823/2-3 (M.H.-L.).

\section{REFERENCES}

1. Dombrovskiy, V. Y., Martin, A. A., Sunderram, J., Paz, H. L. (2007) Rapid increase in hospitalization and mortality rates for severe sepsis in the United States: a trend analysis from 1993 to 2003. Crit. Care Med. 35, 1244-1250

2. Kochanek, K. D., Smith, B. L. (2004) Deaths: preliminary data for 2002. Natl. Vital. Stat. Rep. 52, 1-47

3. Riedemann, N. C., Guo, R. F., Ward, P. A. (2003) The enigma of sepsis. J. Clin. Invest. 112, 460-467

4. Ward, P. A. (2004) The dark side of C5a in sepsis. Nat. Rev. Immunol. 4, 133-142

5. Wang, H., Bloom, O., Zhang, M., Vishnubhakat, J. M., Ombrellino, M., Che, J., Frazier, A., Yang, H., Ivanova, S., Borovikova, L., Manogue, K. R., Faist, E., Abraham, E., Andersson, J., Andersson, U., Molina, P. E., Abumrad, N. N., Sama, A., Tracey, K. J. (1999) HMG-1 as a late mediator of endotoxin lethality in mice. Science 285, 248-251

6. Lotze, M. T., Tracey, K. J. (2005) High-mobility group box 1 protein (HMGB1): nuclear weapon in the immune arsenal. Nat. Rev. Immunol. 5, 331-342

7. Weaver, C. T., Hatton, R. D., Mangan, P. R., Harrington, L. E. (2007) IL-17 family cytokines and the expanding diversity of effector T cell lineages. Annu. Rev. Immunol. 25, 821-852

8. Kolls, J. K., Linden, A. (2004) Interleukin-17 family members and inflammation. Immunity 21, 467-476

9. Schwarzenberger, P., La Russa, V., Miller, A., Ye, P., Huang, W., Zieske, A., Nelson, S., Bagby, G. J., Stoltz, D., Mynatt, R. L., Spriggs, M., Kolls, J. K. (1998) IL-17 stimulates granulopoiesis in mice: use of an alternate, novel gene therapy-derived method for in vivo evaluation of cytokines. J. Immunol. 161, 6383-6389

10. Ye, P., Rodriguez, F. H., Kanaly, S., Stocking, K. L., Schurr, J., Schwarzenberger, P., Oliver, P., Huang, W., Zhang, P., Zhang, J., Shellito, J. E., Bagby, G. J., Nelson, S., Charrier, K., Peschon, J. J., Kolls, J. K. (2001) Requirement of interleukin 17 receptor signaling for lung CXC chemokine and granulocyte colonystimulating factor expression, neutrophil recruitment, and host defense. J. Exp. Med. 194, 519-527

11. Chabaud, M., Fossiez, F., Taupin, J. L., Miossec, P. (1998) Enhancing effect of IL-17 on IL-1-induced IL-6 and leukemia inhibitory factor production by rheumatoid arthritis synoviocytes and its regulation by Th2 cytokines. J. Immunol. 161, $409-414$

12. Van Kooten, C., Boonstra, J. G., Paape, M. E., Fossiez, F., Banchereau, J., Lebecque, S., Bruijn, J. A., De Fijter, J. W., Van Es, L. A., Daha, M. R. (1998) Interleukin-17 activates human renal epithelial cells in vitro and is expressed during renal allograft rejection. J. Am. Soc. Nephrol. 9, 1526-1534

13. Benchetrit, F., Ciree, A., Vives, V., Warnier, G., Gey, A., SautesFridman, C., Fossiez, F., Haicheur, N., Fridman, W. H., Tartour, E. (2002) Interleukin-17 inhibits tumor cell growth by means of a T-cell-dependent mechanism. Blood 99, 2114-2121

14. Linden, A. (2001) Role of interleukin-17 and the neutrophil in asthma. Int. Arch. Allergy. Immunol. 126, 179-184

15. Shibata, K., Yamada, H., Hara, H., Kishihara, K., Yoshikai, Y. (2007) Resident Vdelta1+ gammadelta T cells control early infiltration of neutrophils after Escherichia coli infection via IL-17 production. J. Immunol. 178, 4466-4472

16. Bettelli, E., Oukka, M., Kuchroo, V. K. (2007) T(H)-17 cells in the circle of immunity and autoimmunity. Nat. Immunol. 8, $345-350$
17. Baker, C. C., Chaudry, I. H., Gaines, H. O., Baue, A. E. (1983) Evaluation of factors affecting mortality rate after sepsis in a murine cecal ligation and puncture model. Surgery 94, 331335

18. Maeda, Y., Reddy, P., Lowler, K. P., Liu, C., Bishop, D. K., Ferrara, J. L. (2005) Critical role of host gammadelta T cells in experimental acute graft-versus-host disease. Blood 106, 749-755

19. Sakai, T., Ohara-Inagaki, K., Tsuzuki, T., Yoshikai, Y. (1995) Host intestinal intraepithelial gamma delta $\mathrm{T}$ lymphocytes present during acute graft-versus-host disease in mice may contribute to the development of enteropathy. Eur. J. Immunol. 25, 87-91

20. Molet, S., Hamid, Q., Davoine, F., Nutku, E., Taha, R., Page, N., Olivenstein, R., Elias, J., Chakir, J. (2001) IL-17 is increased in asthmatic airways and induces human bronchial fibroblasts to produce cytokines. J. Allergy Clin. Immunol. 108, 430-438

21. Ferretti, S., Bonneau, O., Dubois, G. R., Jones, C. E., Trifilieff, A. (2003) IL-17, produced by lymphocytes and neutrophils, is necessary for lipopolysaccharide-induced airway neutrophilia: IL-15 as a possible trigger. J. Immunol. 170, 2106-2112

22. Awane, M., Andres, P. G., Li, D. J., Reinecker, H. C. (1999) NF-kappa B-inducing kinase is a common mediator of IL-17-, TNF-alpha-, and IL-1 beta-induced chemokine promoter activation in intestinal epithelial cells. J. Immunol. 162, 5337-5344

23. Yokota, N., Daniels, F., Crosson, J., Rabb, H. (2002) Protective effect of $\mathrm{T}$ cell depletion in murine renal ischemia-reperfusion injury. Transplantation 74, 759-763

24. Park, H., Li, Z., Yang, X. O., Chang, S. H., Nurieva, R., Wang, Y. H., Wang, Y., Hood, L., Zhu, Z., Tian, Q., Dong, C. (2005) A distinct lineage of $\mathrm{CD} 4 \mathrm{~T}$ cells regulates tissue inflammation by producing interleukin 17. Nat. Immunol. 6, 1133-1141

25. Wynn, T. A. (2005) $\mathrm{T}(\mathrm{H})-17$ : a giant step from $\mathrm{T}(\mathrm{H}) 1$ and $\mathrm{T}(\mathrm{H})$ 2. Nat. Immunol. 6, 1069-1070

26. Wilson, N. J., Boniface, K., Chan, J. R., McKenzie, B. S., Blumenschein, W. M., Mattson, J. D., Basham, B., Smith, K., Chen, T., Morel, F., Lecron, J. C., Kastelein, R. A., Cua, D. J., McClanahan, T. K., Bowman, E. P., de Waal Malefyt, R. (2007) Development, cytokine profile and function of human interleukin 17-producing helper T cells. Nat. Immunol. 8, 950-957

27. Harrington, L. E., Hatton, R. D., Mangan, P. R., Turner, H., Murphy, T. L., Murphy, K. M., Weaver, C. T. (2005) Interleukin 17-producing $\mathrm{CD} 4+$ effector $\mathrm{T}$ cells develop via a lineage distinct from the T helper type 1 and 2 lineages. Nat. Immunol. 6, 1123-1132

28. Acosta-Rodriguez, E. V., Napolitani, G., Lanzavecchia, A., Sallusto, F. (2007) Interleukins lbeta and 6 but not transforming growth factor-beta are essential for the differentiation of interleukin 17-producing human T helper cells. Nat. Immunol. 8, 942-949

29. Denning, T. L., Wang, Y. C., Patel, S. R., Williams, I. R., Pulendran, B. (2007) Lamina propria macrophages and dendritic cells differentially induce regulatory and interleukin 17 producing T cell responses. Nat. Immunol. 8, 1086-1094

30. Zhou, L., Ivanov, I. I., Spolski, R., Min, R., Shenderov, K., Egawa, T., Levy, D. E., Leonard, W. J., Littman, D. R. (2007) IL-6 programs $\mathrm{T}(\mathrm{H})-17$ cell differentiation by promoting sequential engagement of the IL-21 and IL-23 pathways. Nat. Immunol. 8, 967-974

31. Mangan, P. R., Harrington, L. E., O'Quinn, D. B., Helms, W. S., Bullard, D. C., Elson, C. O., Hatton, R. D., Wahl, S. M., Schoeb, T. R., Weaver, C. T. (2006) Transforming growth factor-beta induces development of the $\mathrm{T}(\mathrm{H}) 17$ lineage. Nature 441, 231234

32. Bettelli, E., Carrier, Y., Gao, W., Korn, T., Strom, T. B., Oukka, M., Weiner, H. L., Kuchroo, V. K. (2006) Reciprocal developmental pathways for the generation of pathogenic effector TH17 and regulatory T cells. Nature 441, 235-238

33. Kebir, H., Kreymborg, K., Ifergan, I., Dodelet-Devillers, A., Cayrol, R., Bernard, M., Giuliani, F., Arbour, N., Becher, B., Prat, A. (2007) Human $\mathrm{T}(\mathrm{H}) 17$ lymphocytes promote bloodbrain barrier disruption and central nervous system inflammation. Nat. Med. 13, 1173-1175

34. Annunziato, F., Cosmi, L., Santarlasci, V., Maggi, L., Liotta, F., Mazzinghi, B., Parente, E., Fili, L., Ferri, S., Frosali, F., Giudici, F., Romagnani, P., Parronchi, P., Tonelli, F., Maggi, E., Romagnani, S. (2007) Phenotypic and functional features of human Th17 cells. J. Exp. Med. 204, 1849-1861 
35. Stumhofer, J. S., Laurence, A., Wilson, E. H., Huang, E., Tato, C. M., Johnson, L. M., Villarino, A. V., Huang, Q., Yoshimura, A., Sehy, D., Saris, C. J., O’Shea, J. J., Hennighausen, L., Ernst, M., Hunter, C. A. (2006) Interleukin 27 negatively regulates the development of interleukin 17-producing T helper cells during chronic inflammation of the central nervous system. Nat. Immunol. 7, 937-945

36. Batten, M., Li, J., Yi, S., Kljavin, N. M., Danilenko, D. M., Lucas, S., Lee, J., de Sauvage, F. J., Ghilardi, N. (2006) Interleukin 27 limits autoimmune encephalomyelitis by suppressing the development of interleukin 17-producing T cells. Nat. Immunol. 7, 929-936

37. Stark, M. A., Huo, Y., Burcin, T. L., Morris, M. A., Olson, T. S., Ley, K. (2005) Phagocytosis of apoptotic neutrophils regulates granulopoiesis via IL-23 and IL-17. Immunity 22, 285-294

38. Matsushima, A., Ogura, H., Fujita, K., Koh, T., Tanaka, H., Sumi, Y., Yoshiya, K., Hosotsubo, H., Kuwagata, Y., Shimazu, T., Sugimoto, H. (2004) Early activation of gammadelta T lymphocytes in patients with severe systemic inflammatory response syndrome. Shock 22, 11-15

39. Hartupee, J., Liu, C., Novotny, M., Li, X., Hamilton, T. (2007) IL-17 enhances chemokine gene expression through mRNA stabilization. J. Immunol. 179, 4135-4141

40. Qian, Y., Liu, C., Hartupee, J., Altuntas, C. Z., Gulen, M. F., Jane-Wit, D., Xiao, J., Lu, Y., Giltiay, N., Liu, J., Kordula, T., Zhang, Q. W., Vallance, B., Swaidani, S., Aronica, M., Tuohy,
V. K., Hamilton, T., Li, X. (2007) The adaptor Act1 is required for interleukin 17-dependent signaling associated with autoimmune and inflammatory disease. Nat. Immunol. $\mathbf{8}$, 247-256

41. Hunter, C. A. (2007) Actl-ivating IL-17 inflammation. Nat. Immunol. 8, 232-234

42. Linden, A., Laan, M., Anderson, G. P. (2005) Neutrophils, interleukin-17A and lung disease. Eur. Respir. J. 25, 159-172

43. Dong, C. (2006) Diversification of T-helper-cell lineages: finding the family root of IL-17-producing cells. Nat. Rev. Immunol. 6, 329-333

44. Iwakura, Y., Ishigame, H. (2006) The IL-23/IL-17 axis in inflammation. J. Clin. Invest. 116, 1218-1222

45. Chung, C. S., Watkins, L., Funches, A., Lomas-Neira, J., Cioffi, W. G., Ayala, A. (2006) Deficiency of gammadelta T lymphocytes contributes to mortality and immunosuppression in sepsis. Am. J. Physiol. Regul. Integr. Comp. Physiol. 291, R1338R1343

46. Huber-Lang, M. S., Younkin, E. M., Sarma, J. V., McGuire, S. R., Lu, K. T., Guo, R. F., Padgaonkar, V. A., Curnutte, J. T., Erickson, R., Ward, P. A. (2002) Complement-induced impairment of innate immunity during sepsis. J. Immunol. 169, 32233231

Received for publication December 31. 2007. Accepted for publication January 31, 2008. 